although Honvan (soluble phosphorylated stilboestrol) may be given intravenously, in a dose of $250 \mathrm{mg}$ daily, to relieve urgent symptoms. This may be followed by Honvan tablets, $100 \mathrm{mg}$ daily, or stilboestrol.

Water retention with risk of heart failure is the most important side effect; there is conflicting evidence about the occurrence of thrombosis during oestrogen therapy in men. Intolerance due to nausea may occur as in women and may be controlled by perphenazine. Testicular atrophy and reduction in libido, together with gynaecomastia and pigmentation of the nipple are almost inevitable side effects.

\section{Carcinoma of the Male Breast}

The treatment of choice for advanced cancer of the breast in the male is bilateral orchidectomy. However, oestrogens are a useful form of therapy in some patients or after orchidectomy has failed, stilboestrol, $5 \mathrm{mg}$ thrice daily, may be given.

\section{Carcinoma of the Thyroid}

Patients who have had radical surgery for carcinoma of the thyroid gland require full thyroid replacement therapy. This may be either with L-thyroxine, $0.3 \mathrm{mg}$ daily in divided doses, or Diotroxin (thyroxine and liothyronine). In addition to fulfilling the normal requirements, by suppressing the production of thyroid stimulating hormone, this treatment may prevent recurrence of the tumour. Larger doses of L-thyroxine $(0.4 \mathrm{mg}$ daily) and tri-iodothyronine ( $200 \mathrm{mg}$ daily) may control recurrent disease and should be tried after other methods of treatment have failed, regardless of the histological type of the tumour.

Primary treatment with L-thyroxine may induce thyrotoxicosis, which presents with the typical features of tachycardia, sweating, heat intolerance, and loss of weight. The dosage should be supervised, as in the presence of cardiac disease it may precipitate complications and lead to cardiac failure.

\section{Conclusions}

Hormones have an important role in the treatment of those types of tumour described as hormone-dependent, and from a clinical point of view much worthwhile palliation is achieved. It is not always easy to decide which hormone should be given, but it must be stressed that if the first tried does not achieve an effect another drug should be substituted. The possibility of endocrine ablation must always be considered.

Though the side-effects of any treatment must not be worse than the disease itself, probably for any patient not yet at the terminal stages it is worst of an to leave incurable disease untreated.

\section{Reference}

1 Thalassinos, N., and Joplin, G. F., British Medical fournal, 1968, 4, 14.
Traditionally the medical school at Newcastle has always taken particular trouble to see that all its students gain some experience of general practice. So it was natural that the university should also be one of the first to have a vocational training scheme for general practice. The trainees on the original course are now about to start their final year, and so far there has been no lack of good calibre applicants to take part in the scheme. In fact, because the organizers were reluctant to turn away some excellent candidates for the second course, which began last year, the scheme was extended to six practices in Teesside.

The idea for the scheme was put forward in the year before the Todd report appeared, when it was already clear what its recommendations about training for general practice were likely to be. A special subcommittee of the regional postgraduate organization was set up, consisting of representatives of all the various interests concerned, with a general practitioner in the chair. This had worked out a detailed set of proposals by the autumn of 1968 , only a few months after the Todd report was published. The first course was advertised in the spring of 1969 and 17 candidates applied, of whom seven were appointed; by the time the second course began, a year later in the late summer of 1970, all the 11 applicants could be accommodated, both in Newcastle and Teesside; this year there were 18 applicants, of whom 13 were appointed, again to both centres. One of the notable features was that not only were local graduates applying to go on the course but that inquiries came from all over Britain and from four overseas countries-and from doctors doing a variety of jobs. These features have continued, although it is obvious that there are now enough schemes elsewhere to offer places for all those who want vocational training.

\section{Curriculum}

The basic pattern of the Newcastle curriculum is much the same as in other schemes: one year in general practice and two in "in service" hospital posts. Unlike most of the other schemes, however, the general practice year is divided into two periods of six months-one at the beginning of the course, the other right at its end. The designers of the course thought it was essential that the trainees should have some idea of what general practice was about, from the start of the course. Administratively, however, this division was difficult to organize, since the regulations state that any trainee allowance will be paid only for a year spent continuously in general practice. Even so, through the local medical committee, the subcommittee managed to persuade the Department of Health to waive this requirement, and certainly this flexibility achieved 
right at the start has typified the shape of the detailed curriculum of the course that followed. Thus most of the trainees have been able to choose four posts out of paediatrics, psychiatry, general medicine, geriatrics, obstetrics, and accident and emergency, depending on their previous experience and inclinations. The aim is that by the end of the course the trainees should be able to sit the examinations for the M.R.C.G.P., the D.C.H., and the D.R.C.O.G. As far as the last two diplomas are concerned several of them have also been able to attend formal courses for these, either at the university or at one of the postgraduate centres.

As at Ipswich (19 June, p. 704), the consultants readily agreed to allocate some of their house jobs to the trainees in the teaching hospital and the peripheral ones; the latter particularly welcomed the idea as the scheme ensured that they received junior staff of a high calibre.

Particular care was taken over selecting general practitioners trainers for the scheme, so that they could guarantee that trainees would get experience of modern group practice which used appointment systems and a full range of ancillary staff. Well before the scheme started local general practitioners who were interested in becoming trainers were asked to fill in a detailed questionnaire asking about their working methods, their partners, equipment and ancillary staff, whether appointment systems were used, and so on. The committee had no difficulty in finding sufficient training practices of the right calibre, and it plans to review these every three years.

\section{Seminars}

Once a week trainees on all the courses and as many trainers as possible attend an afternoon seminar run by the lecturer in family medicine. For part of this, the journal club, the doctors split into groups, at which the trainees present and discuss various papers in turn. The other part is an "asking the experts" session, attended, say, by a consultant, a worker in another academic discipline, or a social worker, who opens the sessions with a short introduction on a given topic, and then takes part in the succeeding discussion. Most of the subjects are chosen for their relevance to an important aspect of general practice which is usually not covered in teaching or in books or journals, and typically, I gathered that these sessions are usually lively and hard-hitting; certainly the one I attended bore out this opinion. What was wrong, the trainees asked the visiting dermatologist, with trying to cure any kind of rash with steroid cream before getting consultant advice? How could they recognize scabies, and was disinfection of all personal clothing and bedclothes as recommended in the textbooks really necessary? What results of practical use were coming out of all the high-powered resèarch going on in the university department of dermatology? Could they send their practice nurses to the skin outpatient department to learn the techniques used there?

These exchanges were by no means one-sided. The dermatologist promised that any patient would be seen at the hospital immediately as an emergency if a doctor asked him to do so; he asked the group if they minded his referring one of their patients to another hospital department without contacting the general practitioner again first, and whether they would prefer to manage patients themselves in their own practice once the diagnosis had been made and the treatment suggested, or whether the skin department should do this.

\section{Views}

The trainees were equally frank when discussing the vocational training course. The design of this, they said, was excellent and its total length about right, but there was a continual risk of their being used as mere pairs of hands, and not true trainees; in fact, they had already suggested to the joint trainers/trainees committee that some posts used for the course should be blacklisted. The accident and emergency job they had found stressing, though they agreed that the experience it gave was invaluable. Paediatrics had been especially popular, the more so as the social side was particularly emphasized. The quality of the seminars varied, and some claimed that having to read journal articles was a chore, but they agreed that regular meetings had helped the group to cohere, much as had the frequent social functions which had been organized by the trainers and trainees.

Such complaints as the trainees had were centred on housing and money. Although they could get married quarters at the peripheral hospitals-and sometimes even retain these during the general practice part of the course-these were not available at the teaching hospital. Because of this most of them had had to buy new houses near their general practices, a heavy expense out of a salary of little over $£ 2,000$. Moreover, they had to have a car, and the basic allowance of $£ 250$ and the tiny mileage rate (over which anyway they might have to haggle) were insufficient to cover their expenses. Surely, I countered, they were no worse off than a registrar on the teaching hospital ladder? They disagreed: for them a house and a car were necessities; a registrar could live in any part of the city and could do without a car. What was more to the point was the financial loss they were making compared with their non-trained contemporaries who were already partners in general practice. Three years of vocational training would leave them worse off by $£ 5,030$, and they suggested that any trainee who completed the course should be paid this sum as a bonus at the end of it.

Those consultants I spoke to had not found that their work had increased through having a trainee as a houseman; in fact, sometimes the reverse was the case, since the trainees were invariably keen doctors and sometimes had considerably more experience than the average resident. Some of the general practitioner trainers, on the other hand, had found the trainees a mixed blessing. Training was for them an unfamiliar role which included teaching sessions in the practice, attending and often preparing for the weekly seminars, and planning and executive committees. Moreover, having a trainee put an extra burden on practice receptionists and secretaries. This was counterbalanced by the in-service contribution of most of the trainees but, they claimed, training was worth more than the $£ 250$ annual trainers' allowance, much of which was swallowed up in providing extra equipment for the trainee and itself $£ 100$ less than the rate for a half-day hospital session as a clinical assistant.

\section{Pattern of Training}

The pattern of training in the first general-practice period had varied. Some trainers had allowed the trainees to have a group of their "own" patients almost from the start; others had thought that a longer period of sitting in on surgery sessions initially was necessary. Others again, from their own past experience, had thought that supervised locums for partners on holiday was good practice in responsibility. In most practices the trainee was first on call for emergencies one night in every four or five, but even so his particular trainer had to be available at the same time as well. For the second period in general practice I gathered that most of the trainers were intending to give the trainees progressively more responsibility, so that they would be ready for an assistantship or junior partnership by the end of the course.

The grant to pay for this training course came, like that at Ipswich, from the research fund of the Department of Health. Though the organizers would like this to be raised-in particular they already need a lot more secretarial help-their greatest concern at present is the way the time spent on administration and teaching has increased now that there are three groups of trainees going through the course simultaneously. The smooth running of the course conceals the 
hours spent in arguing various points with the many sectional interests concerned. A lot more time is spent on the constant scrutiny of the curriculum and the jobs themselves, while the whole project is one of those included in a survey for the Department of Health-so that trainers and trainees alike are subjected to regular batches of intelligence and attitude tests. Given also that some of the trainers are concerned with teaching family medicine to undergraduates, and it is easy to see why one trainer told me he hoped that some scheme of rotation of teaching practices would be worked out to let them have an occasional rest. Clearly many of these problems will be solved with time, but one hopes that none of the present zest for this kind of scheme will be lost from this brave start at Newcastle upon Tyne.

\section{Any Questions?}

We publish below a selection of questions and answers of general interest

\section{Aspirin, Phenylbutazone and Anticoagulants}

Should drugs such as aspirin or phenylbutazone which are apt to cause gastric bleeding be given to patients taking anticoagulants, and vice versa?

It is generally said that both aspirin and phenylbutazone should not be given to patients who are on anticoagulant therapy. This is not only because these drugs may cause local gastric irritation and bleeding. Both drugs also potentiate the action of the oral anticoagulants of the coumarin group. Acetylsalicylic acid, but no other salicylates, prolongs the prothombin time. Large doses of aspirin alone are required to do this, but if given along with an oral anticoagulant therapeutic doses, such as those which may be used in the treatment of rheumatoid arthritis, can have a potentiating effect.

Watson and Pierson ${ }^{1}$ in a study in which they measured the blood loss from the gastrointestinal tract in patients on oral anticoagulants found that the addition of aspirin in a dose of $600 \mathrm{mg}$ q.d.s. did not increase the amount of bleeding.

Phenylbutazone potentiates the action of the coumarin anticoagulants by competitive displacement of the coumarin drug from the specific binding sites to plasma albumin, thus releasing additional amounts of free anticoagulant. ${ }^{2}$ There is, therefore, an increased risk of bleeding particularly from the gastrointestinal tract in a patient who is on anticoagulant therapy if he is given either aspirin or phenylbutazone. Whether this can be regarded as an acceptable risk will depend upon the circumstances of the individual patient and in particular on how carefully the therapeutic regimen can be supervised.

1 Watson, R. M., and Pierson, R. N., Circulation, 1961, 24, 613.

2 Kazmier, F. J., and Spittell, J. A., Mayo Clinic Proceedings, 1970, $45,249$.

\section{Fungi in Infusions}

What effects could the inadvertent administration of an intravenous infusion containing fungi of the ascomycete group be expected to have? If there were no apparent immediate effects could there be any delayed effects?

The ascomycetes are a large group of fungi characterized by the formation of ascospores inside a sac or ascus. They include such species as aspergillus and penicillin. Such fungi are ubiquitous and have often been found contaminating infusion fluids. A review of the harmful effects of particles found in intravenous fluid, including fungi, has been published, ${ }^{1}$ though the fungal fragments, possibly being introduced during sterilization, may not always be viable.
The experimental intravenous administration of live spores of aspergillus into rabbits produces death in unprotected animals after periods of three to four and a half days, ${ }^{2}$ with microscopic lesions involving all the organs. These consist of a marked inflammatory cell reaction around fragments of hyphae or large collections of macrophages containing material suggestive of fungal matter. Mucor species produce similar results. ${ }^{3}$

Mice given intravenous injections of aspergillus spores ${ }^{4}$ develop marked neurological signs after 2-10 days, the most constant symptom being torticollis. Microscopic invasion of blood vessel walls in the cerebrum and cerebellum and even aspergillomata are found at necropsy. The kidneys may also be affected.

The effects of intravenous infusion of fungi depend upon the dose of spores actually received, the clinical state of the patient, and whether he is receiving corticosteroid therapy, which predisposes to harmful effects by all opportunist organisms. The inadvertent administration of fungal contaminated intravenous fluids has happened before. ${ }^{5}$ The effects upon the human recipient, judging from the animal experiments, might be extremely harmful unless treatment is instituted within a few hours using amphotericin B in a dose of $0.25 \mathrm{mg}$ per kg body weight given by intravenous drip in $5 \%$ dextrose solution. Such treatment for a single period of 24 hours produced no harmful effects from this toxic drug in two patients who have since remained perfectly well for periods of almost two years. The rationale behind the treatment, which is based on the animal experiments described above, is to inhibit the fungal elements before they can penetrate the capillaries and, having become embedded in inflammatory exudate, become relatively inaccessible to the antibiotic.

Whether this treatment is indicated in any given case must be decided from the circumstances, especially the dose of spores received, concurrent corticosteroid therapy, and the time lapse since the infusion. The long-term results in an untreated patient have not been published, so far as I am aware. One patient in my experience who was accidentally transfused with fluid containing ascomycete spores and candida was not treated for a matter of days and died. No postmortem examination was done, and the patient may well have died of her original disease in any event. Some filamentous fungi and some yeast-like fungi may not be sensitive to amphotericin $\mathbf{B}$.

\footnotetext{
Garvan, J. M, and Gunner, B. W., Medical Fournal of Australia, 1964

2. 1. J. H., and Baker, R. D., Antibiotics and Chemotherapy, 1959,
2 Evans, J.

3 Chick, E. W. Evans, J., and Baker, R. D., Antibiotics and Chemo-

therapy, 1958, 8. 394.
Pore, R. S., and Larch, H. W., Sabouraudia, 1968, 6, 89.

5 Robertson, M. H., fournal of Medical Microbiology, 1970, 3, 99.
} 